\section{Novel use of the Heald anal stent after transanal endoscopic microsurgery}

\author{
Alun E. Jones, Guy F. Nash \\ Department of General Surgery, Poole \\ General Hospital, Dorset, UK
}

Distension of the rectum following transanal endoscopic microsurgery (TEMS) increases rectal intra-luminal pressure and may promote pelvic sepsis by contaminating the rectal defect. We describe the first use of a Heald anal stent to decompress the rectum following TEMS. Transanal endoscopic microsurgery (TEMS) is an increasingly popular method of resecting rectal neoplasms with minimal morbidity and mortality. Following excision of the lesion, the defect in the rectal wall is usually repaired by a continuous suture. However there is no evidence to suggest defect closure is superior to leaving this to heal by secondary intention. Distension of the rectum post-operatively increases rectal intra-luminal pressure and may promote pelvic sepsis by contaminating the rectal defect.

The anal stent (Figure 1), devised by Professor Heald, has previously been described as a technique in decompressing a leaking ileorectal anastomosis, thus avoiding reoperation. ${ }^{1}$ The original objective of this silastic stent was to protect low colo-rectal anastomosis by stenting open the anus. A small randomised controlled trial has previously shown this approach to be a safe alternative to a temporary defunctioning loop stoma. ${ }^{2}$

We used the anal stent in a novel way in a 70-year-old male patient who underwent a full thickness TEMS resection, complicated by pelvic sepsis, to reduce the positive intra-rectal pressure. The rectal defect, which was left open, resulted in pelvic sepsis, characterised by pyrexia, lower abdominal pain and urinary retention. The stent was inserted painlessly on the ward (Figure 2), and in the three days following its insertion, the patient's clinical condition and inflammatory markers rapidly improved, and he was discharged, requiring no further intervention.

In the absence of an anal stent, a Foley catheter may similarly be used to decompress rectal or pelvic collections. However urinary catheters more frequently become blocked and

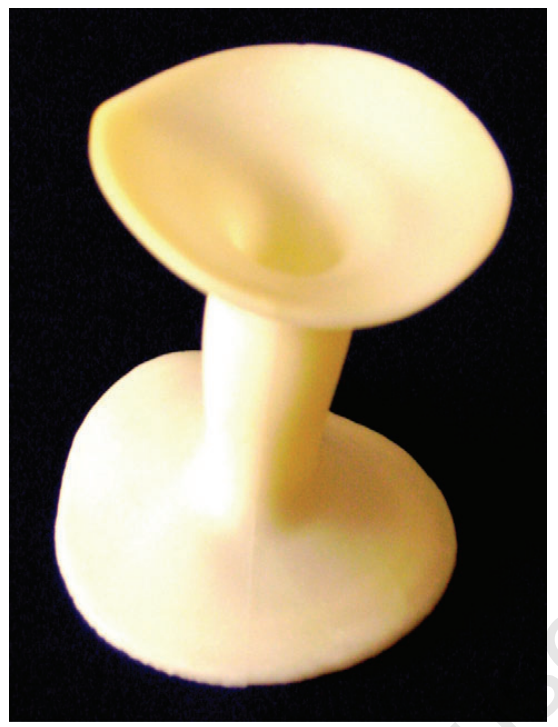

Figure 1. The hollow, silastic Heald anal stent.

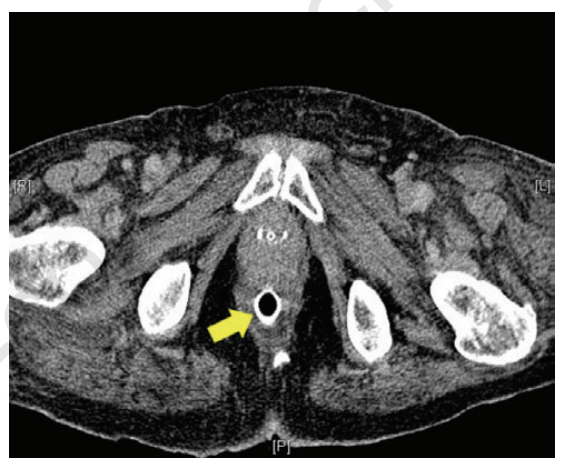

Figure 2. Computed tomography scan of the pelvis demonstrating decompression of the rectum after insertion of the transanal stent. The middle (barrel) of the stent can be seen in the rectal ampulla (arrow).
Correspondence: Guy F. Nash, Department of General Surgery, Poole General Hospital, Dorset, UK BH15 2JB. Tel. +44.01201.555511.

E-mail: guy.nash@poole.nhs.uk

Key words: transanal endoscopic microsurgery, anal stent

Contributions: AEJ and GFN wrote the article, GFN reviewed it.

Conflict of interest: the authors report no conflicts of interest.

Received for publication: 5 July 2011

Accepted for publication: 28 August 2011.

This work is licensed under a Creative Commons Attribution NonCommercial 3.0 License (CC BYNC 3.0).

(C) Copyright A.E. Jones, G.F. Nash, 2011 Licensee PAGEPress, Italy

Surgical Techniques Development 2011; 1:e15 doi:10.4081/std.2011.e15

are not tolerated as well as the anal stent, which is also easy to irrigate if necessary. The short, wide lumen of the anal stent facilitates the drainage of both gas and fluid.

Other possible uses of the transanal stent are to decompress the rectum in other clinical scenarios, such as decompressing leaks at the proximal limb following pouch surgery and decompressing the rectal stump after emergency subtotal colectomy for acute colitis.

\section{References}

1. Therapeutic use of the Heald Silastic Anal Stent. Colorectal Dis 2007;9:279-80.

2. Amin AI, Ramalingam T, Sexton R, et al. Comparison of transanal stent with defunctioning stoma in low anterior resection for rectal cancer. Br J Surg 2003;90: 581-2. 